\title{
Inflammation of the retinal pigment epithelium: a unique presentation of ocular schistosomiasis
}

\author{
A Jane Dickinson, A Ralph Rosenthal, Karl G Nicholson
}

\begin{abstract}
We report the first case of inflammation of the retinal pigment epithelium (RPE) caused by Schistosoma mansoni and discuss its possible pathogenesis. This is of particular interest because the lesions resembled those found in acute multifocal placoid pigment epitheliopathy (AMPPE).
\end{abstract}

Schistosomiasis affects 200 million people throughout the world, and its associated morbidity and mortality are thus of major importance. On contact with infected water it takes only minutes for cercarciae to enter skin, though the eyeball resists penetration. ${ }^{1}$ The young organisms quickly reach cutaneous venules, and thereafter remain intravascular. They must reach the liver in order to mature, and they then migrate into the portal caval venous circulation or occasionally pulmonary arterioles, where they mate and lay eggs.

The chief lesion of schistosomiasis is an intravascular obstructive process: either a granuloma or a hypersensitive vascular response, and as only mature worms or ova excite this response it is usually confined to the portal caval venous circulation and adjacent viscera, reactions to worms or ova elsewhere being defined as ectopic. ${ }^{2}$ Symptomatic ectopic infections with $S$ mansoni are particularly rare,,${ }^{34}$ though necropsy studies suggest that asymptomatic lesions of the central nervous system may be common. ${ }^{5}$

\section{Case report}

A 17-year-old man presented with profound right visual deterioration and an itchy eruption on his forehead, both of two weeks' duration. He had recently returned from Tanzania, where he previously lived, and recalled a febrile illness with myalgia and diarrhoea shortly after swimming in Lake Victoria six weeks previously. $\mathrm{He}$ had taken no antimicrobials in the recent past.

Examination revealed a papular eruption over the left forehead (Fig 1). from which a small biopsy was taken. Visual acuity was $6 / 60$ right eye and $6 / 5$ left eye, with a right afferent pupil defect and a mild right iridocyclitis. Funduscopy of the right eye revealed optic disc swelling and multiple creamy lesions confined to the superotemporal quadrant, clinically at the level of the RPE, with intraretinal exudates round the fovea (Fig 2). On fluorescein angiography the creamy lesions showed early masking of the choriocapillaris (Fig 3), and there was hyperfluorescence of the superotemporal disc margin followed by generalised disc leakage. By four minutes all creamy lesions were hyperfluor-

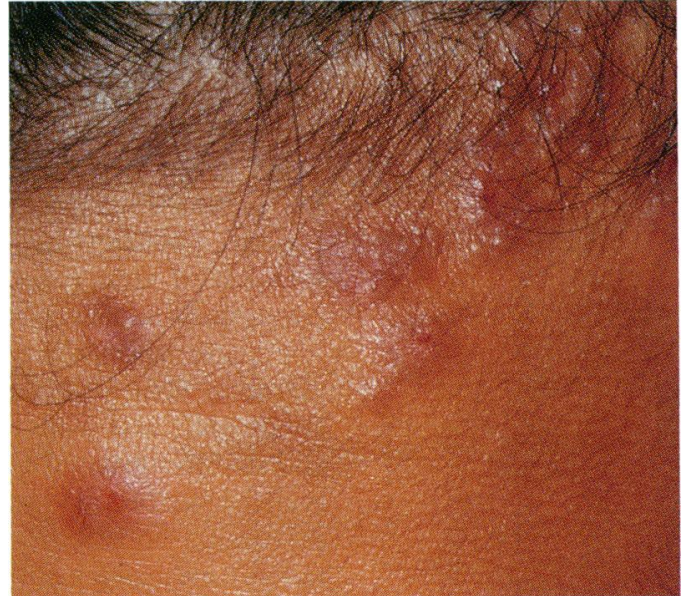

Figure 1: Papular eruption over the left forehead, extending to the midline.

escent, some with persistent central masking (Fig 4), but the macular exudates did not fluoresce. The left eye was normal and a general examination showed nothing abnormal.

Histological examination of the skin biopsy specimen showed two ova of Schistosoma mansoni with numerous eosinophils. The patient had a

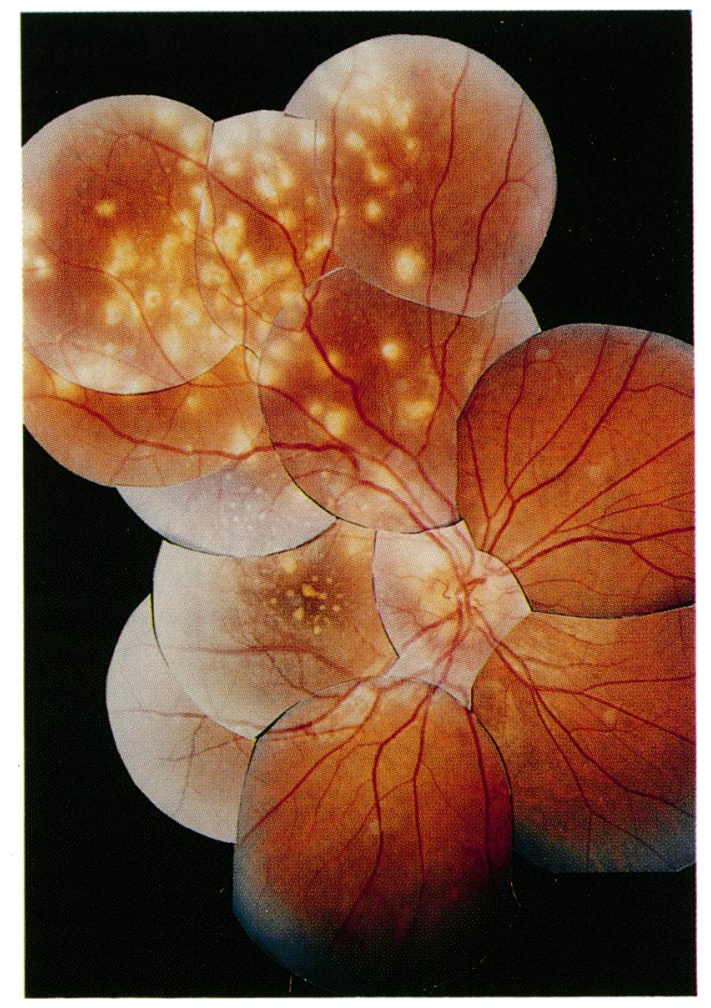

Figure 2: Right fundus, showing sectoral distribution of creamy lesions, clinically at the level of the RPE, with intraretinal exudates at the fovea and slight swelling of the optic disc.
Accepted for publication

23 January 1990 


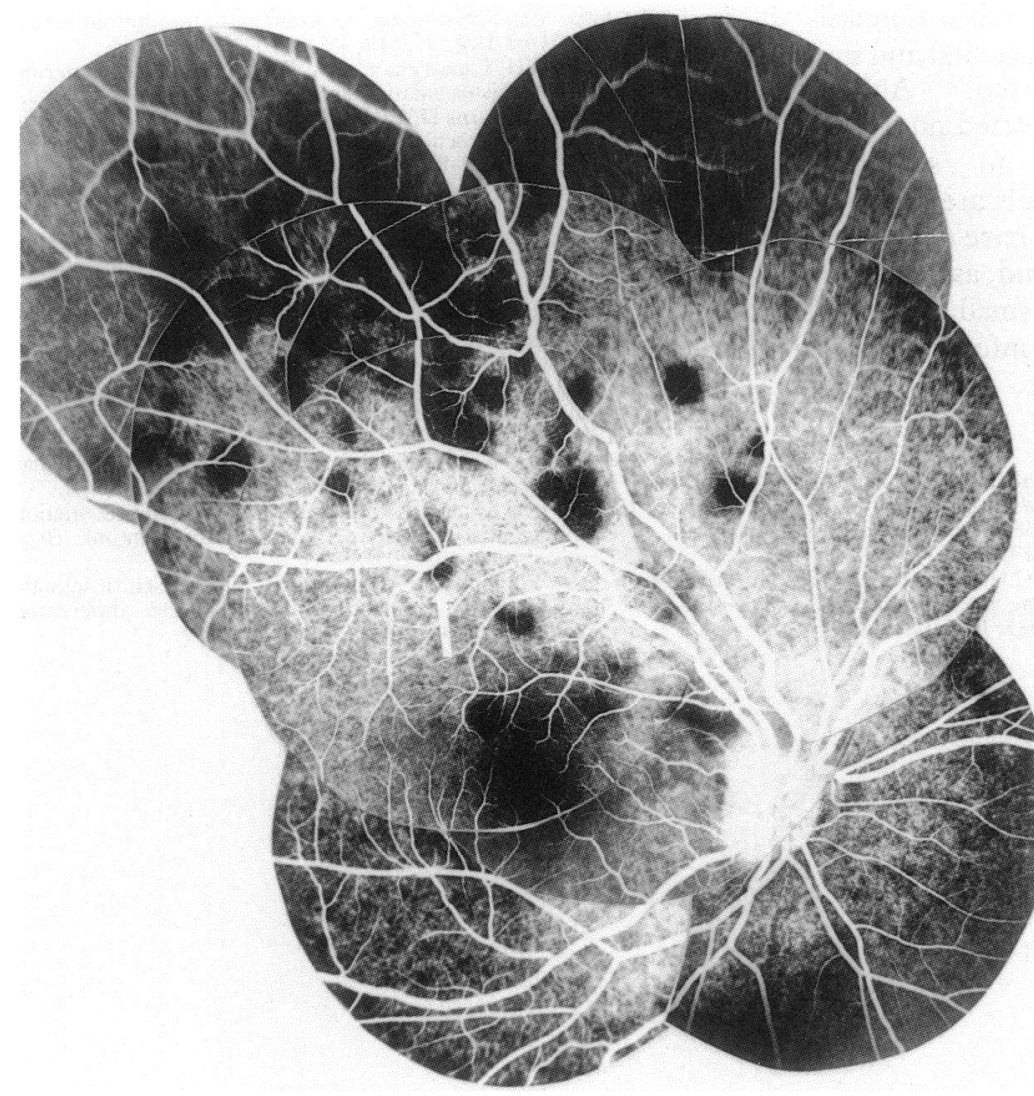

Figure 3: Arteriovenous phase of fluorescein angiogram showing masking of the choriocapillaris by the RPE lesions. (Arrow indicates lesion shown in Fig 4.)

$47 \%$ eosinophilia (leucocytes $5 \cdot 3 \times 10^{9} / 1$ ). Stool examination revealed numerous $S$ mansoni ova; urine examination gave negative results. The enzyme-linked immunosorbent assay for schistosomal antibody was positive at level 1 , later rising to level 4 . Chest $X$-ray and liver function tests were normal, and serological tests negative for toxocara, toxoplasma, and syphilis.

Six weeks after treatment with praziquantel (40 $\mathrm{mg} / \mathrm{kg}$ body weight given once) the skin lesions had resolved. The right visual acuity had improved to $6 / 5$, with resolution of the disc

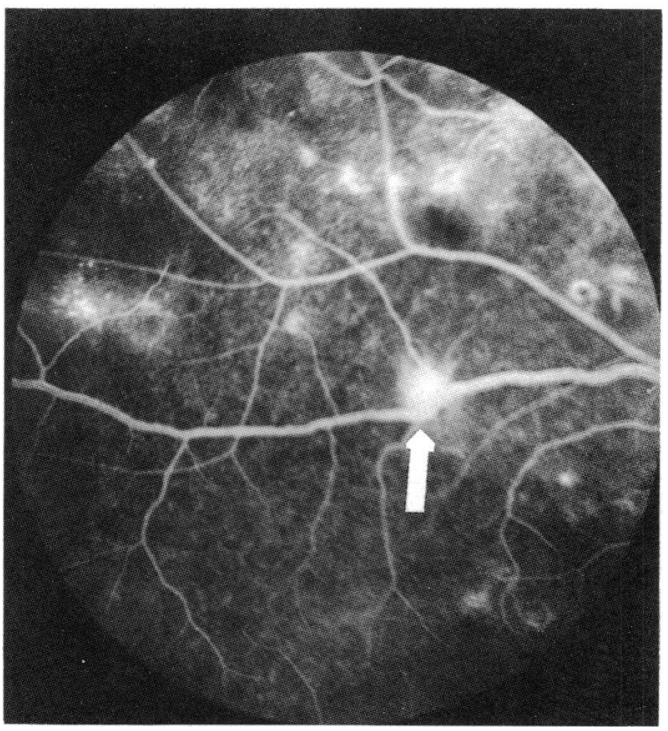

Figure 4: Fluroescein angiogram after six minutes, with most initially masked areas now hyperfluorescent. (Arrow indicates lesion seen in Fig 3.) swelling and exudates, and the fundal lesions had evolved into chorioretinal, centrally pigmented scars (Fig 5). Repeat fluorescein angiography showed no disc leakage, but was otherwise unchanged. He has remained well since.

\section{Discussion}

The skin lesion in this patient, which has been reported on elsewhere, ${ }^{6}$ is likely to have contained numerous ova. This suggests ectopic worm migration, with local oviposition, rather than egg embolism.

The ocular lesions may be explained in two ways. It is most probable that the disease was primarily within the choroidal circulation, with either ova, worms, or a hypersensitive response in the choriocapillaris causing secondary ischaemia or inflammation in the RPE and disc. Choroidal granulomas round $S$ mansoni ova have been reported, ${ }^{7}$ and in an experimental model of ascarid endophthalmitis RPE lesions developed secondarily to an eosinophilic choroiditis and far from any organism. ${ }^{8}$

Alternatively the disease may have primarily affected the retina. The sectoral distribution of lesions round a single retinal vessel is more suggestive of retinal than choroidal disease, and the exudates indicate retinal involvement, though they may have been a secondary phenomenon. If the lesions were centred on ova, then either eggs were laid by a worm at the disc or mechanical factors directed all eggs to one vessel. The disc oedema and afferent pupil defect certainly imply disc inflammation, but as female worms measure $0.2 \times 25 \mathrm{~mm}$ it is hard to envisage a worm in the vessels at the disc without evidence of vessel obstruction.

The creamy lesions in this patient had the clinical and angiographic appearances of those found in AMPPE. Although it is still argued that this may be a primary inflammation of the RPE, the more favoured hypothesis is that it is due to immune-complex induced vascular obstruction of the choriocapillaris with subsequent RPE ischaemia. ${ }^{910}$ We believe that vascular obstruction of the choriocapillaris either by ova or a hypersensitivity response caused the RPE lesions in this patient.

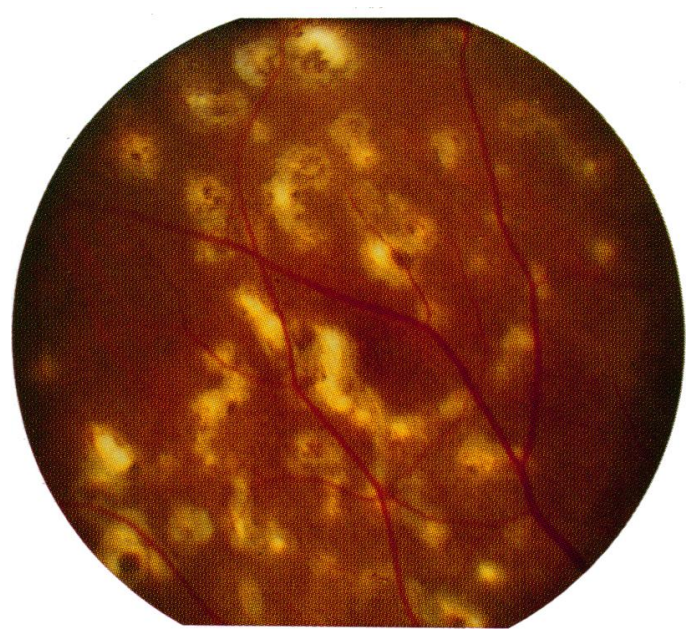

Figure 5: Superotemporal area of right fundus two months after treatment, with semiconfluent chorioretinal scars. 
Given the scale of schistosomiasis it is surprising that both extragenital and intraocular lesions are so rarely reported. ${ }^{11-13}$ Abboud et al's study of 150 patients detected no ocular lesions definitely attributable to schistosomiasis,' though examination details are lacking. Nevertheless, necropsy studies have demonstrated ova in up to $56 \%$ of brains, ${ }^{3}$ and, as fundi may not be routinely examined and small granulomas hard to visualise, ${ }^{8}$ intraocular infection may be more common than is apparent.

1 Ábboud IA, Hanna LS, Ragab HAA. Experimental ocular schistosomiasis. Br f Ophthalmol 1971; 55: 106-15.

2 Faust EC. An inquiry into the ectopic lesions in schistosomiasis. Am 7 Trop Med Hyg 1948; 28: 175-99.

3 Scrimgeour EM, Gajdusek DC. Involvement of the central nervous system in Schistosoma mansoni and $S$ haematobium infection. A review. Brain 1985; 108: 1023-38.
4 Chityo ME. Schistosomal involvement of the choroid plexus. Cent Afr F Med 1972; 18: 45-7.

5 Pittella JEH, Lana-Peixoto MA. Brain involvement in hepatosplenic schistosomiasis mansoni. Brain 1981; 104: 621-32.

6 Milligan A, Burns DA. Ectopic cutaneous schistosomiasis and schistosomal ocular inflammatory disease. Br $\mathcal{F}$ Dermatol schistosomal ocular

7 Pittella JEH, Orefice F. Schistosomotic choroiditis: II. Report of first case. Brf Ophthalmol 1985; 69: 300-2.

8 John T, Barsky HJ, Donnelly JJ, Rockey JH. Retinal pigmen epitheliopathy and neuroretinal degeneration in ascaridinfected eyes. Invest Ophthalmol Vis Sci 1987; 28: 1583-98.

9 Young NJA, Bird AC, Sehmi K. Pigment epithelial diseases with abnormal choroidal perfusion. Am f Ophthalmol 1980; 90: 607-18.

10 Lyness AL, Bird AC. Recurrences of acute posterior multifocal placoid pigment epitheliopathy. Am $\mathcal{f}$ Ophthalmol 1984; 98: 203-7.

11 Newton JC, Kanchanaranya C, Previte LR Jr. Intraocular Schistosoma mansoni. Am f Ophthalmol 1968; 65: 774-8.

12 Jacyk WK, Lawande RV, Tulpule SS. Unusual presentation of extragenital cutaneous schistosomiasis mansoni. $\mathrm{Br} \mathcal{F}$ Dermatol 1980; 103: 205-8.

13 Orefice F, Simal CJR, Pittella JEH. Schistosomotic choroiditis: I. Funduscopic changes and differential diagnosis. Br f Ophthalmol 1985; 69: 294-9. 